\title{
Prototype Wind Turbine Design
}

\author{
Dilek Özlem Esen* and Serkan Keskin \\ Kocaeli University Technology Faculty Automotive Engineering, Turkey \\ ${ }^{*}$ Corresponding author
}

\begin{abstract}
Wind energy, which has a high potential in renewable energy sources, has a capacity to meet the rapidly growing energy need. In a wide variety of fields and different types of turbines, the wind energy we use can easily be used in lowvoltage devices such as simple household appliances. Within the context of this study, fundamentals of wind turbines have been introduced. Besides, wind turbine design, information about elements in horizontal axis wind turbine and turbine power account are taken up. The phases of construction of the prototype wind turbine have been examined primarily. Finally, it is explained how a small-scale wind turbine can be designed and how the turbine power calculation is made. Furthermore, the measurement of the power capacity of the energy obtained from the generated wind turbine has been carried out.
\end{abstract}

\section{Keywords—wind turbine; prototype; design}

\section{INTRODUCTION}

Speaking countries in the world economy make significant investments in renewable energy sources and are making great efforts to increase the use of these resources. The energy that has become the indispensable part of our experience; when it is supplied from renewable sources, it leads to environmental pollution during production, transportation and consumption. Renewable energy sources do not pollute the environment and the long life of these resources is a great advantage in meeting the energy need. One of the most advantageous sources of renewable energy sources is wind energy. Increasing use of electronic devices and the amount of energy consumed by these appliances are now increasing. Given this situation, the difference between energy production and consumption is increasing day by day. In order to close this energy gap, different ways of energy production are emphasized. One of these ways is wind energy from renewable energy sources [1]. In this project, the design of the prototype wind turbine and the calculation of the turbine power are emphasized in order to introduce the wind turbines and take advantage of the wind energy. First, the materials to be used for the wind turbine have been identified. The voltage values obtained from the assembled turbine were then converted to power via the data logger. Another aim of this work is to be a preliminary project for the construction of medium-sized wind turbines that can be used in residential buildings.

\section{TURKEY'S Wind ENERgy POTENTIAL}

The studies for the promotion of the use in Turkey for the last period in the frequent electricity production of renewable energy systems on the agenda, after the determination of the 2023 targets by all official institutions and organizations as well as industry-related non-governmental organizations are also accelerated.According to information the Energy and Natural
Resources Ministry made 50 meters above ground level for Turkey, 7.5 meter / second on areas with wind speed, kilometer $5 \mathrm{MW}$ wind is accepted that Power Plant installed. [2]Thus, Turkey's wind energy potential is determined to be $48000 \mathrm{MW}$. This sum corresponds to the potential area corresponding to $1.30 \%$ of Turkey's surface (See Figure I-II).

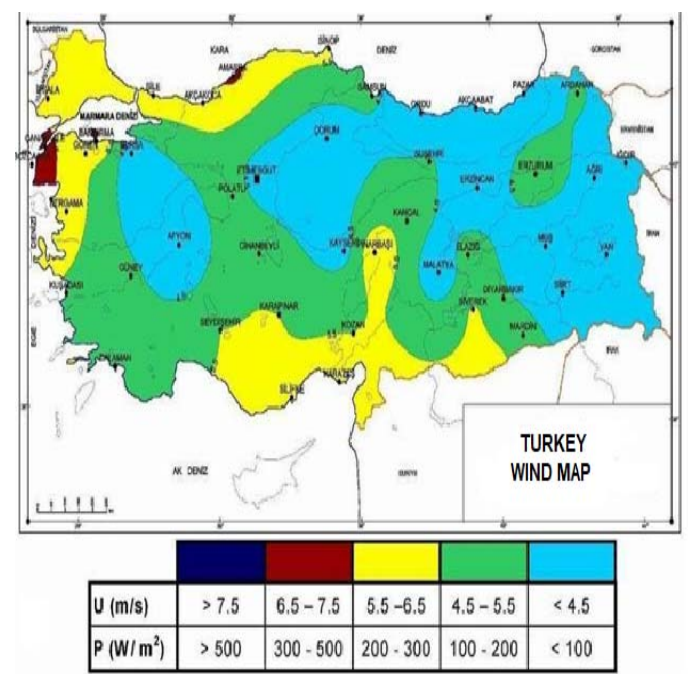

FIGURE I. THE AVERAGE WIND SPEED MEASURED AT $50 \mathrm{M}$

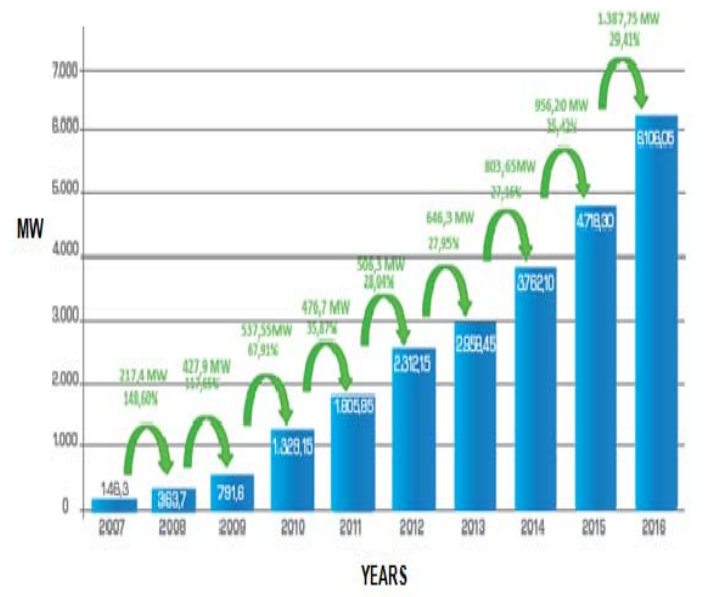

FIGURE II. THE CUMULATIVE INSTALLATION FOR WIND POWER HEIGHT FOR TURKEY PLANTS IN TURKEY

Since 2006, Turkey has gained momentum in investment in wind energy and has continued at full speed. The source of significant developments after 2006 is Law No. 5346 on the Usage of Renewable Energy Sources for Electricity Generation 
Purposes published on 10.05.2005. At the end of 2009, the year of the publication of the strategy document, the installed capacity was $791.6 \mathrm{MW}$. With the investments to be made at the end of 14 years, it is targeted to increase this figure to approximately 25 times. When Turkey's potential is considered, it is understood easily that actually represents a value of less than half of the wind energy potential of this figure. Work is continuing without slowing down in order to make it possible to reach these targets with a correct road map. 20072016 from below with the wind power plants in Turkey we can see the breakdown by years of cumulative capacity [3].Wind Map, generally gives an idea about wind energy distribution in Turkey. Wind potentials of 50 meters in Kocaeli city.

\section{Wind TURBINE ELEMENTS, TURBINE DESIGN AND TURBINE POWER ACCOUNT}

It consists of a wind turbine, a tower at the height where the obstacles in the surroundings can not blow the wind, a body and a rotord placed thereon. The high wind speed also allows the high speed portion of the near-earth wind profile to be used.The kinetic energy of the wind is converted to the mechanical energy of the rotor [4].The rotation of the rotor shaft is accelerated and the generator in the body is transferred. The electric energy obtained from the generator is used by storing it by means of a charger or by directly reaching the receiver. The main elements that make up the modern wind turbines can be listed as follows.Tower, Body, Gear box, Generator, Low speed high speed mill, Speed controller, Orientation driver and orientation motor, Electronic control unit, Hydraulic system, Cooling unit, Wings, Wind measurement receiver, Slope mechanism, Brakes.For the calculation of the energy generated by a wind turbine, the speed of the wind and the diameter of the propeller are needed. Most large wind turbines spin at about 15 meters / second.Theoretically, it is necessary to increase the diameter of the propeller to increase the generated energy. This means that the height of the wind turbine also increases. This takes more wind and provides a faster rotation [5]. Since the specific mass of air is small, the energy from the wind depends on the wind speed. The speed of the wind increases with the height, and the power increases with the speed of the cube. The energy that the wind will provide depends on its power and the number of blows. Specific wind force is the force that falls to the surface of the unit perpendicular to the airflow (See Figure III-IV).

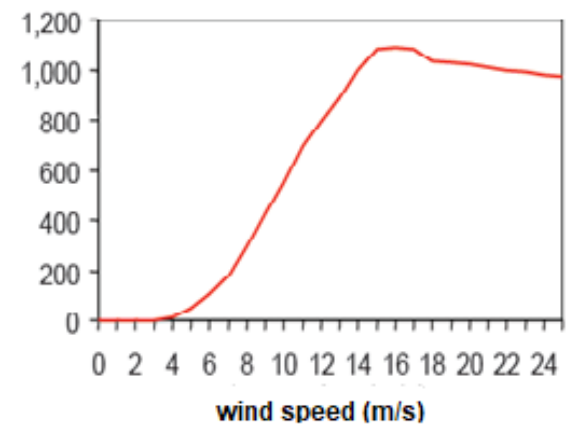

FIGURE III. POWER CURVE FOR 1 MW TURBINE

\begin{tabular}{|c|c|}
\hline $\begin{array}{c}\text { Propeller Height and Maximum Power Output } \\
\text { propeller diameter }(\mathbf{m})\end{array}$ & power output (kW) \\
\hline 10 & 25 \\
\hline 17 & 100 \\
\hline 27 & 225 \\
\hline 33 & 300 \\
\hline 40 & 500 \\
\hline 44 & 600 \\
\hline 48 & 750 \\
\hline 54 & 1000 \\
\hline 64 & 1500 \\
\hline 72 & 2000 \\
\hline 80 & 2500 \\
\hline
\end{tabular}

FIGURE IV. AVERAGE TURBINE POWERS BY PROPELLER DIAMETER

$\mathrm{P}=1 / 2$. $\rho \cdot \mathrm{V}^{3} \cdot \mathrm{C}_{\mathrm{p}} \cdot \mathrm{A}$, Here, $\mathrm{P}=$ Power (Watt), ${ }^{1 / 2}=$ Constant, $\rho$ $=$ Air Density $\left(\mathrm{kg} / \mathrm{m}^{3}\right), \mathrm{V}=$ Wind Speed Power, $\mathrm{C}_{\mathrm{p}}=$ Power Coefficient, $\mathrm{A}=$ Swept Area $\left(\mathrm{m}^{2}\right), \mathrm{E}=\mathrm{P} . \Delta \mathrm{t}$ (3.3) Here; $\mathrm{t}$ : Time (taken as 8760 hours), [6]

\section{Prototype Wind Turbine DESIGN}

Wind turbines are systems that convert kinetic energy in the wind to mechanical energy by means of wings and then to electric energy by the rotor. These systems have small, medium and large scale capacities and meet various energy needs. Here, the following methods are used to construct the prototype wind turbine with the simplest structure and minimum cost materials. The wings are made of 5-inch pimas pipes made of PVC material. 5 pieces $218 \mathrm{~mm}$ long wings can be removed and repaired in order to be able to repair $95 \mathrm{~mm}$ diameter fiberglass plate with 2 bolts on the $460 \mathrm{~mm}$ diameter turbine propeller was obtained. It is understood that the number of blades in lowspeed turbines is very high, and that the number of blades in high-speed turbines is low, there is an inverse relationship between the number of blades and the end speed ratio. The use of three wings is generally preferred because of its smoother rotation. In this study, five wings were used in this type because of the low blade size and low wind speed. It is aimed to provide a balanced rotation by adding various weights to balance the rear parts of the turbine wheel. (See Figure V-VI)

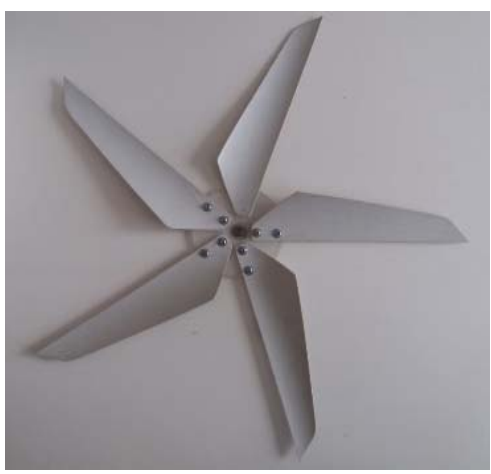

FIGURE V. TURBINE PROPELLER 


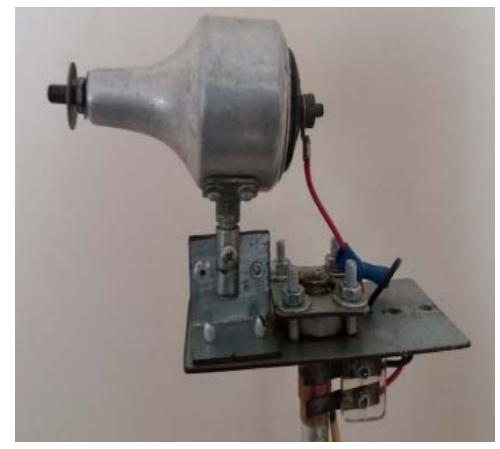

FIGURE VI. DYNAMO

Motor, gear box, power circuit, rectifier, etc. to turn kinetic energy into electric energy. equipment can be used. In this project, the dynamo in 12 volt, 6 watt power used on bicycles is converted to electric energy from the wind. This wind turbine can be observed by means of led lamps connected to dinamoya where power can be generated.In order to be able to benefit from the winds that are exerted in various directions, it is desirable that the turbine body be at a vertical position at all times to the wind direction. The dynamo is placed on a metal table which is supported by a bearing so that it can rotate freely according to the wind direction. Made of PVC foam and a $3 \mathrm{~mm}$ thick 190mmx190mm Foreks made of wind rose tail. The metal part with $10 \mathrm{~mm}$ diameter PVC pipe is connected with 2 bolts so that the part of the guide is light.The metal plate is placed on a $10 \mathrm{~mm}$ diameter $415 \mathrm{~mm}$ long aluminum pipe which serves as a tower with the help of bearings. The aluminum pipe is secured by securing it in the metal pipe of $20 \mathrm{~mm}$ diameter and $160 \mathrm{~mm}$ length with the help of silicone. (See Figure VII-VIII)

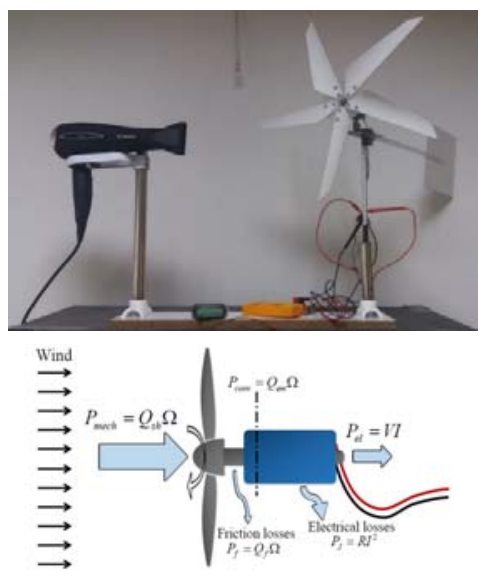

FIGURE VII. TEST BENCH AND ENERGY TRANSFORMATION

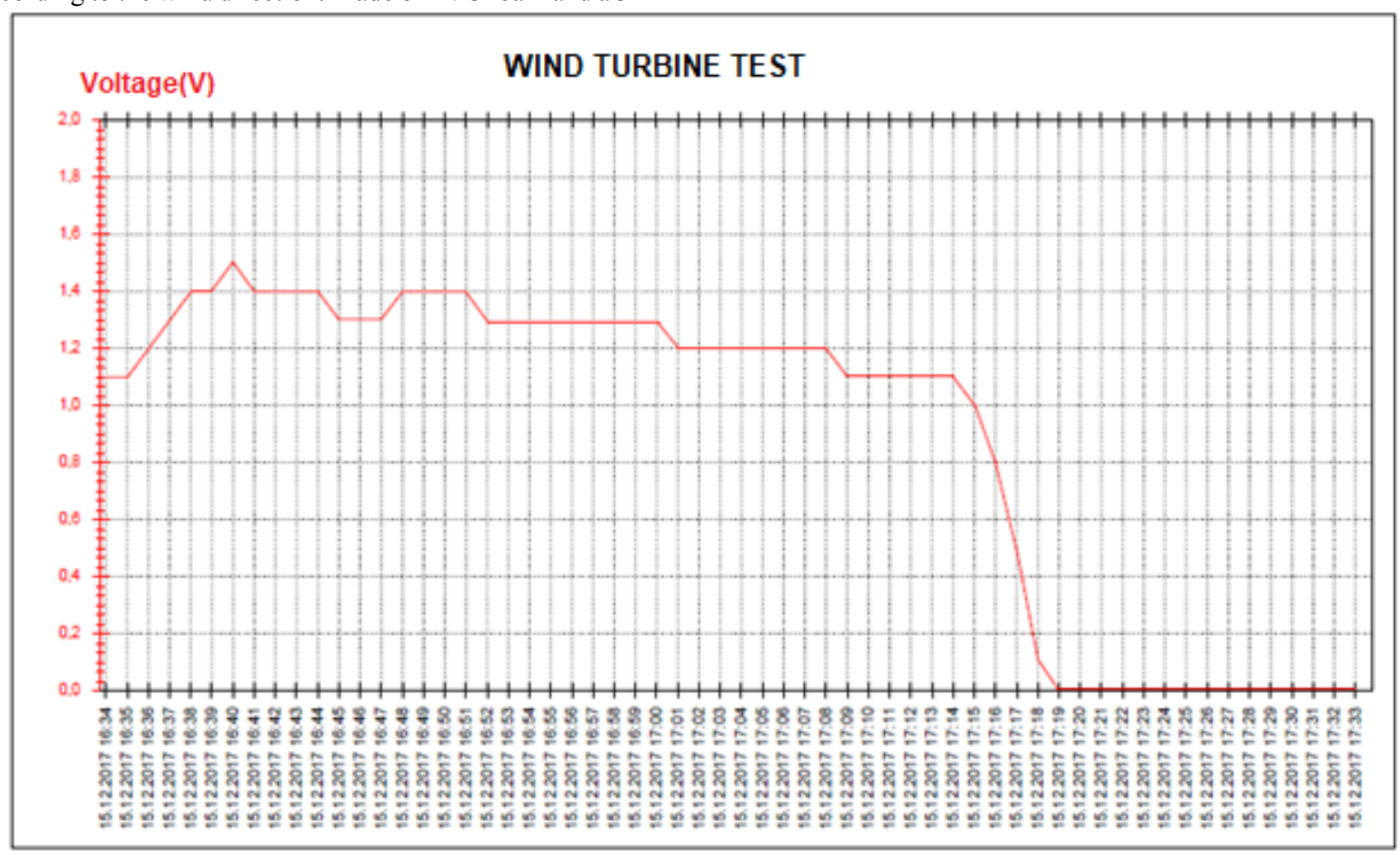

\section{FIGURE VIII. CURVE GRAPH OF THE VOLTAGE READ BY THE TURBINE'S DATALOGGER}

Thus, the tower of the prototype wind turbine was built and a PPRC (Polypropylene Random Copolymer) material was used and a T-pipe reduced from $32 \mathrm{~mm}$ to $20 \mathrm{~mm}$ was used to place the tower on a ground. The pipe was separated into two and secured to the tower floor with the help of 2 bolts. With the aid of an anemometer, the wind gauge obtained from the gauge was measured. With the aid of the datalogger, the voltage voltage data obtained from the prototype wind turbine 
generated is transferred to the computer. The following table for the system has been obtained.

$$
\mathrm{A}=\pi \mathrm{R}^{2}=0,664 \mathrm{~m}^{2}, \mathrm{P}=1 / 2 \cdot \rho \cdot \mathrm{V}^{3} \cdot \mathrm{CP} \cdot \mathrm{A}(3 \cdot 5), \mathrm{V}=4 \mathrm{~m} / \mathrm{s}
$$
average

$\rho=1,225 \mathrm{~kg} / \mathrm{m}^{3}, \mathrm{C}_{\mathrm{P}}=0.5926, \mathrm{P}=1 / 2 \times 1,225 \times 43 \times 0,5926$ x $0,664=15 \mathrm{~W}$

\section{CONCLUSION AND RECOMMENDATIONS}

Today, the use of wind energy is becoming increasingly widespread. Turkey has also accelerated the work on this issue.In this study, prototype design and manufacture of a wind turbine that meets our small energy needs with minimum cost has been realized. The designed bearing system of the turbine center of gravity is mounted and the turbine is freely rotated in the tower axis.Turbine movement was provided with artificial wind generated by the Fön machine. With the datalogger connected to the turbine, the voltage generated in the turbine dinamos was measured and a power calculation was made. It can be seen that the generated prototype wind turbine can generate energy at 15 watt power. With this energy obtained, illumination is provided by LED lamps.In addition, a battery can be easily charged using the additional charge controller and rectifiers. The developed prototype is recommended as a model with very assertive that can be taken as basis for wind turbine design. If and Western Turkey, particularly Marmara for heating the water used in tourist facilities, stored energy available in the energy of the wind can be utilized

\section{REFERENCES}

[1] Ayhan, B.Boru, I Cesur, D Keles, T. Koç, A. Parla Bir Rüzgar Türbini Tasarımı ve Geliștirilmesi, SAÜ Fen Bil. Der. 2013 17(2) 207-216.

[2] http://www.ritm.gov.tr/guc/ritm_tr.html

[3] Turkey Wind Energy Statistics Report, TWESR, 5-18, 2017.

[4] N. Bekiroğlu, O. Kıncay, Z. Yumurtacı, Wind Energy Part I, Yıldız Tech. University, 2004.

[5] http://www.eere.energy.gov/RE/wind technologies.html, (Ziyaret tarihi: 2 Aralık 2017)

[6] İ. Aydın, R. Köse., Electric Power Plant with a Small Powerful Autonomous Wind Energy Conversion System, Electronic Journal of Machine Technologies, 2011, 8(4), 11-28.

[7] N.Jeckins, J. F. Walker, Wind Energy Technology, 1997. 